\title{
Prognostic value of increased expression of RACO-I in patients with hepatitis B-related hepatocellular carcinoma
}

This article was published in the following Dove Press journal:

Therapeutics and Clinical Risk Management

15 February 2017

Number of times this article has been viewed

Jian-yao Chen'

Li-ping Liu ${ }^{2}$

Jiang-feng $\mathrm{Xu}^{3}$

'Department of Hepatobiliary Surgery, Shaoxing Second Hospital, Shaoxing, ${ }^{2}$ Department of Surgery, Zhuzhou Clinical Institute, Central South University School of Medicine, Zhuzhou, ${ }^{3}$ Department of Surgery, The Fourth Affiliated Hospital of Zhejiang University School of Medicine, Yiwu, China
Correspondence: Jiang-feng $\mathrm{Xu}$ Department of Surgery, The Fourth Affiliated Hospital of Zhejiang University School of Medicine, Shangchen Road NI, Yiwu, Zhejiang, 322000, China

Email zjxujiangfeng@hotmail.com
Abstract: RING domain AP-1 coactivator-1 (RACO-1) is a coactivator that links c-Jun to growth factor signaling and is essential for AP-1 function. This study aimed to investigate the expression and clinical significance of RACO-1 protein in hepatitis B virus (HBV)related hepatocellular carcinoma (HCC) in China. A total of 136 tissue samples of HBVrelated $\mathrm{HCC}$ were detected by immunohistochemistry (including 76 patients in training cohort and 60 patients in validation cohort). Correlation between RACO-1 expression and clinicopathologic features of HBV-related HCC was analyzed in both the cohorts. RACO-1 expression was significantly higher in HBV-related HCC tissues than in adjacent non-tumor liver tissues. All the patients were divided into two groups: the low expression group and the high expression group. RACO-1 expression was significantly related to vascular invasion ( $P=0.021)$, tumor numbers $(P=0.046)$, International Union for Cancer Control/American Joint Committee on Cancer stage $(P=0.006)$, cirrhosis $(P=0.046)$, capsular $(P=0.039)$, and Barcelona Clinic Liver Cancer stage $(P=0.041)$ in training cohort. The validation cohort showed the same results. The high RACO-1 expression was the independent prognostic factor for HBV-related HCC patients in both training cohort and validation cohort. Our data implicate RACO-1 as a novel prognostic marker and a potential therapeutic target for HBV-related HCC.

Keywords: RACO-1, hepatitis B, hepatocellular carcinoma, prognosis, BCLC stage, vascular invasion, cirrhosis, UICC/AJCC stage

\section{Background}

Hepatocellular carcinoma (HCC) is one of the most common carcinomas in the world, especially in China. Most of the HCC in China is hepatitis B virus (HBV)-related which is caused by the high HBV infection rates. ${ }^{1-3}$ Although the overall survival of patients with HBV-related HCC had been improved, the survival still remains unsatisfactory. ${ }^{4,5}$ Therefore, it is very important to find novel prognostic markers and potential therapeutic target for HBV-related HCC.

Previous studies have shown that AP-1 transcription factor c-Jun is overexpressed in many human cancers. ${ }^{6-8}$ RING domain AP-1 coactivator-1 (RACO-1) is a c-Jun coactivator that is regulated by growth factor signaling. RACO-1 depletion decreased the expression of several AP-1 target genes, such as $c d c 42, c y c l i n D 1$. RACO-1 also has an important relationship with Wnt signaling and Ras. ${ }^{9,10}$ However, the role of RACO-1 in HBV-related HCC has not been demonstrated. Whether RACO-1 has an effect on the prognosis of HBV-related HCC is still unknown. This study aimed to investigate the effects of RACO-1 on HBV-related HCC and find out the relationship between RACO-1 and the prognosis of HBV-related HCC. 


\section{Methods}

\section{Patients and specimens}

In this study, $\mathrm{HCC}$ was diagnosed and staged according to both the Barcelona Clinic Liver Cancer (BCLC) stage system and International Union for Cancer Control (UICC)/American Joint Committee on Cancer (AJCC) stage system. HCC and the adjacent non-tumor liver tissue (ANLT) specimens were obtained from $136 \mathrm{HBV}$-related HCC patients during surgical resection without any preoperative treatment at the Department of Hepatobiliary Surgery, Shaoxing Second Hospital, and Department of Surgery, Zhuzhou Clinical Institute, Central South University (CSU) School of Medicine from March 2008 to March 2014. The follow-up status and any recurrence were regularly updated in the database for each patient. Our research was in compliance with the Helsinki Declaration. Prior written informed consent was obtained from all patients. The ethics committees of Shaoxing Second Hospital, Zhuzhou Clinical Institute of CSU, and the Fourth Affiliated Hospital of Zhejiang University School of Medicine gave ethics approval for this study and approved the consents. Before the operations, we evaluated the complete blood count, liver function, computed tomography (CT) scan of liver and other tests if necessary. Liver resection was undertaken in patients with Pugh-Child grades A or B.

\section{Immunohistochemistry (IHC)}

Formalin-fixed paraffin sections were stained for RACO-1 using anti-human RACO-1 antibody (Abcam, Cambridge, UK). The expression level of RACO-1 was scored as: $1,1 \%-25 \%$ positive; $2,26 \%-50 \%$ positive; $3,>50 \%$ positive. The protein expression of RACO- 1 was thus considered low expression if scored 1; score 2 or 3 was considered as high expression. Correlation between RACO-1 expression and clinicopathologic features of HBV-related HCC were analyzed in both the cohorts.

\section{Statistical analysis}

Data in the study was analyzed by the Statistical Package for the Social Sciences (SPSS) 19 for Windows (SPSS Inc., Chicago, IL, USA). Fisher's exact test was used for the statistical analysis of categorical data, whereas independent $t$-tests were used for continuous data. The log-rank test was used to compare the overall and disease-free survival. The Cox proportional hazards regression model was established to identify factors that were independently associated with the survival of HCC patients. $P<0.05$ was considered to be statistically significant.

\section{Results \\ Clinical features of patients and the correlations of RACO-I expression with the clinical characteristics of HBV-related $\mathrm{HCC}$}

A total of 136 tissue samples of HBV-related HCC were detected by IHC, including 76 patients in training cohort and 60 patients in validation cohort (Figure 1). There is no significant difference between training cohort and validation cohort (Table 1). RACO-1 expression was significantly high in HBV-related HCC tissues in both training cohort and
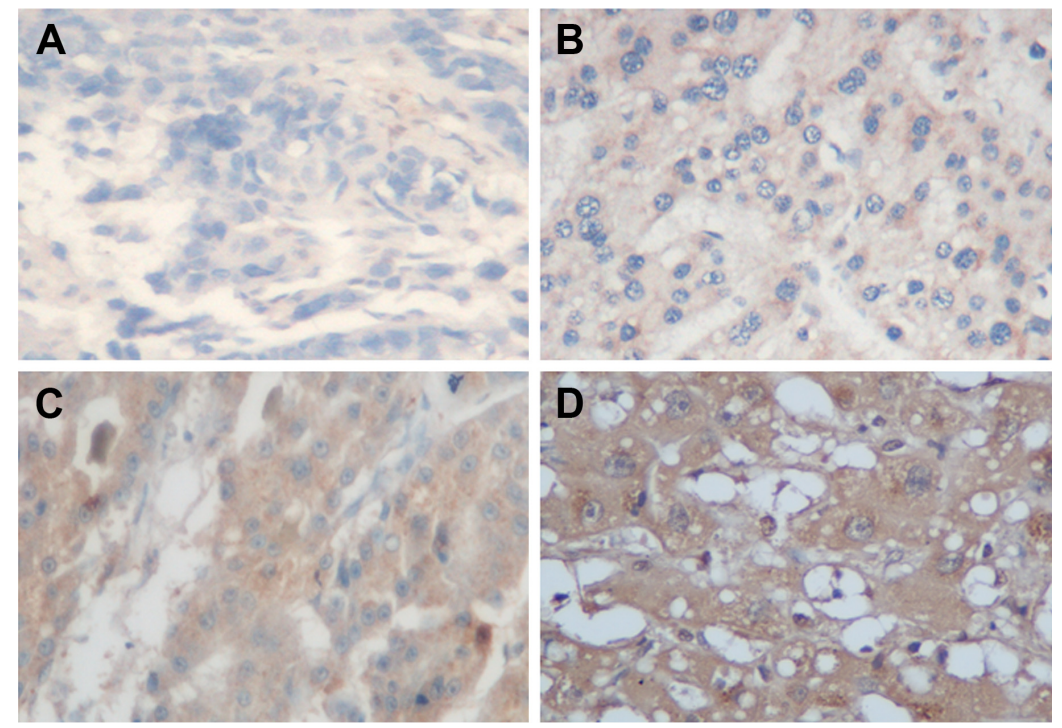

Figure I Immunohistochemistry of RACO-I expression in HBV-related HCC tissues.

Notes: (A-D) These representative images show negative control-isotype control (scored as $0, \mathbf{A}), 1 \%-25 \%$ of cancer cells (scored as I+, B), $26 \%-50 \%$ of cancer cells (scored as $2+, \mathbf{C}$ ), and $>51 \%$ of cancer cells (scored as $3+$, D); original magnification $\times 400$.

Abbreviations: RACO-I, RING domain AP-I coactivator-I; HBV, hepatitis B virus; HCC, hepatocellular carcinoma. 
Table I Clinicopathologic variables of training cohort and validation cohort

\begin{tabular}{|c|c|c|c|}
\hline $\begin{array}{l}\text { Clinicopathologic } \\
\text { variables }\end{array}$ & $\begin{array}{l}\text { Training } \\
\text { cohort (n) }\end{array}$ & $\begin{array}{l}\text { Validation } \\
\text { cohort }(n)\end{array}$ & $P$-value \\
\hline \multicolumn{4}{|l|}{ Gender } \\
\hline Female & 24 & 19 & \multirow[t]{2}{*}{0.642} \\
\hline Male & 52 & 41 & \\
\hline \multicolumn{4}{|l|}{ Age (years) } \\
\hline$\leq 60$ & 60 & 50 & \multirow[t]{2}{*}{0.665} \\
\hline$>60$ & 16 & 10 & \\
\hline \multicolumn{4}{|l|}{ Liver cirrhosis } \\
\hline Presence & 40 & 31 & \multirow[t]{2}{*}{0.645} \\
\hline Absence & 36 & 29 & \\
\hline \multicolumn{4}{|l|}{ Tumor number } \\
\hline Solitary & 36 & 30 & \multirow[t]{2}{*}{0.168} \\
\hline Multiple & 40 & 30 & \\
\hline \multicolumn{4}{|l|}{ Tumor size } \\
\hline$\leq 5 \mathrm{~cm}$ & 36 & 28 & \multirow[t]{2}{*}{0.635} \\
\hline$>5 \mathrm{~cm}$ & 40 & 32 & \\
\hline \multicolumn{4}{|l|}{ Capsular formation } \\
\hline Presence & 35 & 29 & \multirow[t]{2}{*}{0.804} \\
\hline Absence & 41 & 31 & \\
\hline \multicolumn{4}{|l|}{ Vascular invasion } \\
\hline Presence & 30 & 26 & \multirow[t]{2}{*}{0.715} \\
\hline Absence & 46 & 34 & \\
\hline \multicolumn{4}{|c|}{ Edmondson-Steiner grade } \\
\hline Low grade (I-II) & 45 & 32 & \multirow[t]{2}{*}{0.803} \\
\hline High grade (III-IV) & 31 & 28 & \\
\hline \multicolumn{4}{|l|}{ UICC/AJCC stage } \\
\hline I & 30 & 25 & \multirow[t]{2}{*}{0.682} \\
\hline II-III & 46 & 35 & \\
\hline \multicolumn{4}{|l|}{ BCLC stage } \\
\hline $0-A$ & 37 & 27 & \multirow[t]{2}{*}{0.811} \\
\hline$B-C$ & 39 & 33 & \\
\hline
\end{tabular}

Abbreviations: AJCC, American Joint Committee on Cancer; BCLC, Barcelona Clinic Liver Cancer; UICC, International Union for Cancer Control.

validation cohort (Tables 2 and $\mathrm{S} 1$ ). It was found that RACO-1 expression negatively correlates with capsular in both training cohort and validation cohort $(P=0.039 ; 0.041)$. The RACO-1 expression in training cohort was positively related to liver cirrhosis $(P=0.046)$, tumor number $(P=0.046)$, vascular invasion $(P=0.021)$, UICC stage $(P=0.006)$, and BCLC stage $(P=0.041)$ (Table 2). While in validation cohort, RACO-1 expression was positively related to liver cirrhosis $(P=0.041)$, tumor number $(P=0.046)$, vascular invasion $(P=0.005)$, UICC stage $(P=0.048)$, and BCLC stage $(P=0.003)$ (Table S1).

\section{Correlations of RACO-I expression with the overall survival of HBV-related HCC}

Overall survival was analyzed according to the expression of RACO-1 both in training cohort and validation cohort. The high level of RACO-1 had worse overall survival rates in both the training cohort and the validation cohort $(P<0.001$; $P<0.001$ ) (Figure 2). In training cohort, we found that RACO-1 expression is one of the important prognostic factors (Table 3). The multivariate cox regression analysis showed the same result in the training cohort. RACO-1 expression
Table 2 Correlations between RACO-I expression and clinicopathologic variables of 76 cases of HBV-related HCC in training cohort

\begin{tabular}{|c|c|c|c|c|}
\hline \multirow[t]{2}{*}{$\begin{array}{l}\text { Clinicopathologic } \\
\text { variables }\end{array}$} & \multirow[t]{2}{*}{ Patients (n) } & \multicolumn{2}{|c|}{$\begin{array}{l}\text { RACO-I } \\
\text { expression levels }\end{array}$} & \multirow[t]{2}{*}{$P$-value } \\
\hline & & Low & High & \\
\hline \multicolumn{5}{|l|}{ Gender } \\
\hline Female & 24 & 7 & 17 & 0.502 \\
\hline Male & 52 & 17 & 35 & \\
\hline \multicolumn{5}{|l|}{ Age (years) } \\
\hline$\leq 60$ & 60 & 19 & 41 & 0.678 \\
\hline$>60$ & 16 & 5 & 11 & \\
\hline \multicolumn{5}{|l|}{ Liver cirrhosis } \\
\hline Presence & 40 & 7 & 33 & 0.046 \\
\hline Absence & 36 & 17 & 19 & \\
\hline \multicolumn{5}{|l|}{ Tumor number } \\
\hline Solitary & 36 & 17 & 19 & 0.046 \\
\hline Multiple & 40 & 7 & 33 & \\
\hline \multicolumn{5}{|l|}{ Tumor size } \\
\hline$\leq 5 \mathrm{~cm}$ & 36 & 9 & 27 & 0.217 \\
\hline$>5 \mathrm{~cm}$ & 40 & 15 & 25 & \\
\hline \multicolumn{5}{|l|}{ Capsular formation } \\
\hline Presence & 35 & 17 & 18 & 0.039 \\
\hline Absence & 41 & 7 & 34 & \\
\hline \multicolumn{5}{|l|}{ Vascular invasion } \\
\hline Presence & 30 & 3 & 27 & 0.021 \\
\hline Absence & 46 & 21 & 25 & \\
\hline \multicolumn{5}{|c|}{ Edmondson-Steiner grade } \\
\hline Low grade (I-II) & 45 & 11 & 34 & 0.185 \\
\hline High grade (III-IV) & 31 & 13 & 18 & \\
\hline \multicolumn{5}{|l|}{ UICC/AJCC stage } \\
\hline I & 30 & 17 & 13 & 0.006 \\
\hline II-III & 46 & 7 & 39 & \\
\hline \multicolumn{5}{|l|}{$\mathrm{BCLC}$ stage } \\
\hline $0-A$ & 37 & 18 & 19 & $0.04 I$ \\
\hline$B-C$ & 39 & 6 & 33 & \\
\hline
\end{tabular}

Note: $P<0.05$ was considered to be statistically significant; significant values are shown in bold.

Abbreviations: AJCC, American Joint Committee on Cancer; BCLC, Barcelona Clinic Liver Cancer; UICC, International Union for Cancer Control; RACO-I, RING domain AP-I coactivator-I; HBV, hepatitis B virus; HCC, hepatocellular carcinoma.

is one of the independent prognostic factors for overall survival of HBV-related HCC. Furthermore, in the validation cohort, the results from the univariate cox regression analysis associated with overall survival also indicated that RACO-1 expression is one of the important prognostic factors (Table $\mathrm{S} 2$ ). The multivariate cox regression analysis also showed that RACO-1 is one of the independent prognostic factors for overall survival of HBV-related HCC.

\section{Correlations of RACO-I expression with the disease-free survival of HBV-related HCC}

Disease-free survival was detected in both training cohort and validation cohort. RACO-1 high expression group had worse disease-free survival in both training cohort and validation cohort $(P<0.001 ; P<0.001)$ (Figure 2). In training cohort, it was found that RACO-1 expression is one of the 

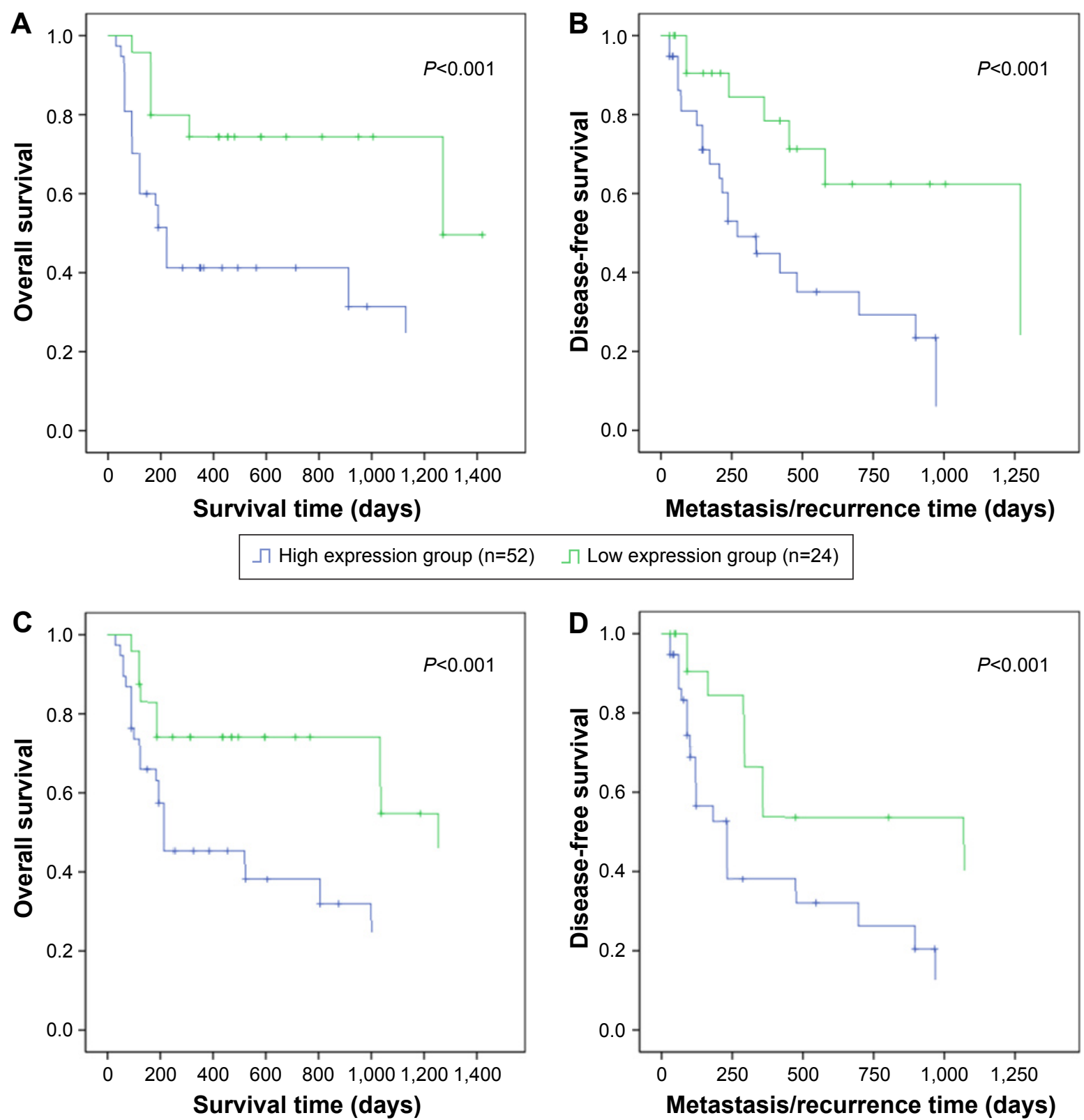

$\neg$ Low expression group $(\mathrm{n}=24)$

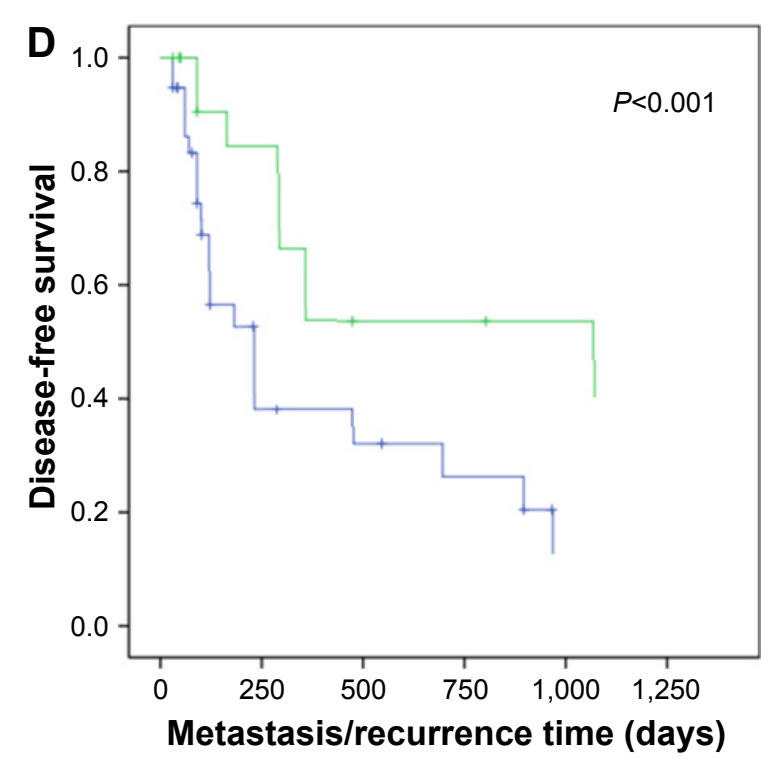

$\neg$ High expression group $(\mathrm{n}=40) \quad \neg$ Low expression group $(\mathrm{n}=20)$

Figure 2 Correlations of RACO-I expression with the overall survival and disease-free survival of HBV-related HCC.

Notes: (A) Overall survival was analyzed according to the expression of RACO-I in training cohort $(P<0.00 \mathrm{I})$. (B) Kaplan-Meier survival curves of disease-free survival in training cohort $(P<0.00 \mathrm{I})$. (C) Overall survival was analyzed according to the expression of RACO-I in validation cohort $(P<0.00 \mathrm{I})$. (D) Kaplan-Meier survival curves of disease-free survival in validation cohort $(P<0.00 \mathrm{I})$.

Abbreviations: RACO-I, RING domain AP-I coactivator-I; HBV, hepatitis B virus; HCC, hepatocellular carcinoma.

important factors together with UICC/AJCC stage, and so on (Table 4). The multivariate cox regression analysis showed RACO-1 expression together with vascular invasion, UICC/ AJCC stage and BCLC stage were independent prognostic factors for disease-free survival of HBV-related HCC. In validation cohort, the result is similar. RACO-1 expression together with UICC/AJCC stage and some other factors were important for prognosis (Table S3). The multivariate cox regression analysis showed that RACO- 1 expression is one of the independent prognostic factors for disease-free survival of HBV-related HCC.

\section{Discussion}

This study aimed to investigate the effects of RACO- 1 on HBV-related HCC. Interestingly, it was found that RACO-1 expression was significantly high in HBV-related HCC tissues 
Table 3 Univariable and multivariable analysis of factors in training cohort associated with overall survival

\begin{tabular}{|c|c|c|c|c|c|}
\hline \multirow[t]{2}{*}{ Variables } & \multirow[t]{2}{*}{ Patients (n) } & \multicolumn{2}{|l|}{ Univariable analysis } & \multicolumn{2}{|c|}{ Multivariable analysis } \\
\hline & & HR (95\% Cl) & $P$-value & HR (95\% Cl) & $P$-value \\
\hline \multicolumn{6}{|l|}{ Gender } \\
\hline Female & 24 & I & & & \\
\hline Male & 52 & $1.654(0.689-6.426)$ & 0.268 & NA & NA \\
\hline \multicolumn{6}{|l|}{ Age (years) } \\
\hline$\leq 60$ & 60 & I & & & \\
\hline$>60$ & 16 & $1.125(0.895-2.102)$ & 0.468 & NA & NA \\
\hline \multicolumn{6}{|l|}{ Liver cirrhosis } \\
\hline Absent & 40 & I & & & \\
\hline Present & 36 & $1.339(0.902-3.125)$ & 0.425 & NA & NA \\
\hline \multicolumn{6}{|l|}{ Tumor number } \\
\hline Solitary & 36 & I & & & \\
\hline Multiple & 40 & $2.932(0.856-3.258)$ & 0.258 & NA & NA \\
\hline \multicolumn{6}{|l|}{ Tumor size } \\
\hline$\leq 5 \mathrm{~cm}$ & 36 & I & & & \\
\hline$>5 \mathrm{~cm}$ & 40 & $1.568(0.957-2.569)$ & 0.368 & NA & NA \\
\hline \multicolumn{6}{|l|}{ Capsular formation } \\
\hline Presence & 35 & I & & 1 & \\
\hline Absence & 41 & $1.654(1.181-3.544)$ & 0.039 & $1.258(1.258-3.985)$ & $0.04 I$ \\
\hline \multicolumn{6}{|l|}{ Vascular invasion } \\
\hline Absent & 30 & I & & I & \\
\hline Present & 46 & $2.802(1.258-4.533)$ & 0.013 & $2.698(1.288-5.010)$ & 0.017 \\
\hline \multicolumn{6}{|c|}{ Edmondson-Steiner grade } \\
\hline Low grade (I-II) & 45 & I & & & \\
\hline High grade (III-IV) & 31 & $1.398(0.862-2.358)$ & 0.099 & NA & NA \\
\hline \multicolumn{6}{|l|}{ UICC/AJCC stage } \\
\hline I & 30 & I & & I & \\
\hline II-III & 46 & $2.685(1.658-3.968)$ & 0.019 & $2.125(1.377-4.457)$ & 0.022 \\
\hline \multicolumn{6}{|l|}{ BCLC stage } \\
\hline $0-A$ & 37 & 1 & & & \\
\hline$B-C$ & 39 & $1.698(1.212-3.682)$ & 0.037 & 1.525 (I.137-3.878) & 0.046 \\
\hline \multicolumn{6}{|l|}{ RACO-I expression } \\
\hline Low & 24 & I & & I & \\
\hline High & 52 & $2.388(1.529-6.587)$ & 0.019 & $2.149(1.689-5.776)$ & 0.022 \\
\hline
\end{tabular}

Note: $P<0.05$ was considered to be statistically significant; significant values are shown in bold.

Abbreviations: AJCC, American Joint Committee on Cancer; BCLC, Barcelona Clinic Liver Cancer; UICC, International Union for Cancer Control; RACO-I, RING domain AP-I coactivator-I; HR, hazard ratio; $\mathrm{Cl}$, confidence interval; NA, not applicable.

in both training cohort and validation cohort. RACO-1 high expression group had worse overall and disease-free survival rates than the low expression group in both training cohort and validation cohort. This indicates that RACO-1 may play an important role in the development of HBV-related HCC and could be a potential target for the treatment of HCC. However, we still do not know the mechanism. This part of work remains to be done in our further research.

Subsequently, the RACO-1 expression was positively related to liver cirrhosis in both training cohort and validation cohort. Most of HCC occurring in China would pass through three steps: HBV infection, liver cirrhosis, and HCC. ${ }^{11-15}$ RACO-1 may play an important role in the development of $\mathrm{HCC}$ by regulating HBV-related cirrhosis.

Interestingly, it is found that RACO-1 expression also has a significant relationship with tumor number, capsular formation, and vascular invasion. Tumor number together with capsular formation and vascular invasion play an important role in the invasion and metastasis of HCC. ${ }^{16-18}$ The present study also showed that RACO-1 expression together with vascular invasion, UICC/AJCC stage, and BCLC stage were independent prognostic factor for overall and disease-free survival of HBV-related HCC. Accordingly, it was speculated that RACO-1 may play an important role in the invasion and metastasis of HBV-related HCC. New research into the potential mechanism of RACO-1 in the invasion and metastasis of HCC has been undertaken.

\section{Conclusion}

In conclusion, it has been shown for the first time that increased expression of RACO-1 is related to worse overall survival in patients with HBV-related HCC. The study 
Table 4 Univariable and multivariable analysis of factors in training cohort associated with disease-free survival

\begin{tabular}{|c|c|c|c|c|c|}
\hline \multirow[t]{2}{*}{ Variables } & \multirow[t]{2}{*}{ Patients (n) } & \multicolumn{2}{|l|}{ Univariable analysis } & \multicolumn{2}{|c|}{ Multivariable analysis } \\
\hline & & HR (95\% Cl) & $P$-value & HR (95\% Cl) & $P$-value \\
\hline \multicolumn{6}{|l|}{ Gender } \\
\hline Female & 24 & 1 & & & \\
\hline Male & 52 & $1.258(0.785-6.125)$ & 0.339 & NA & NA \\
\hline \multicolumn{6}{|l|}{ Age (years) } \\
\hline$\leq 60$ & 60 & 1 & & & \\
\hline$>60$ & 16 & $1.950(0.818-4.58)$ & 0.415 & NA & NA \\
\hline \multicolumn{6}{|l|}{ Liver cirrhosis } \\
\hline Absent & 40 & 1 & & & \\
\hline Present & 36 & $1.308(0.785-3.988)$ & 0.329 & NA & NA \\
\hline \multicolumn{6}{|l|}{ Tumor number } \\
\hline Solitary & 36 & 1 & & & \\
\hline Multiple & 40 & $2.058(0.820-3.158)$ & 0.208 & NA & NA \\
\hline \multicolumn{6}{|l|}{ Tumor size } \\
\hline$\leq 5 \mathrm{~cm}$ & 36 & 1 & & & \\
\hline$>5 \mathrm{~cm}$ & 40 & $1.512(0.688-2.155)$ & 0.312 & NA & NA \\
\hline \multicolumn{6}{|l|}{ Capsular formation } \\
\hline Presence & 35 & 1 & & 1 & \\
\hline Absence & 41 & $1.398(1.117-3.128)$ & 0.039 & $1.258(0.689-3.023)$ & 0.089 \\
\hline \multicolumn{6}{|l|}{ Vascular invasion } \\
\hline Absent & 30 & 1 & & 1 & \\
\hline Present & 46 & 2.125 (1.286-3.786) & 0.018 & $2.133(1.365-4.013)$ & 0.026 \\
\hline \multicolumn{6}{|c|}{ Edmondson-Steiner grade } \\
\hline Low grade (I-II) & 45 & 1 & & & \\
\hline High grade (III-IV) & 31 & I.I88 (0.890-2.3।8) & 0.123 & NA & NA \\
\hline \multicolumn{6}{|l|}{ UICC/AJCC stage } \\
\hline I & 30 & 1 & & 1 & \\
\hline II-III & 46 & $2.339(1.205-3.683)$ & 0.025 & $2.056(1.237-4.384)$ & 0.037 \\
\hline \multicolumn{6}{|l|}{ BCLC stage } \\
\hline $0-A$ & 37 & 1 & & & \\
\hline$B-C$ & 39 & $1.288(1.012-3.127)$ & 0.039 & $1.512(1.087-3.233)$ & 0.041 \\
\hline \multicolumn{6}{|l|}{ RACO-I expression } \\
\hline Low & 24 & 1 & & I & \\
\hline High & 52 & $2.072(1.268-4.658)$ & 0.011 & $2.233(1.304-4.285)$ & 0.029 \\
\hline
\end{tabular}

Note: $P<0.05$ was considered to be statistically significant; significant values are shown in bold.

Abbreviations: AJCC, American Joint Committee on Cancer; BCLC, Barcelona Clinic Liver Cancer; UICC, International Union for Cancer Control; RACO-I, RING domain AP-I coactivator-I; HR, hazard ratio; $\mathrm{Cl}$, confidence interval; NA, not applicable.

implicates RACO-1 as a novel prognostic marker and a potential therapeutic target for HBV-related HCC.

\section{Acknowledgments}

This work was supported by the grants from Natural Science Foundation of Zhejiang province (LQ15H160007); science and technology innovation project of Shaoxing (2016CX017); and scientific research project of Department of Education of Zhejiang province (Y20141279).

\section{Disclosure}

The authors report no conflicts of interest in this work.

\section{References}

1. Yin JW, Ping Huang M, Zhong B. Intrahepatic Toll-like receptor 3 in chronic HBV infection subjects: asymptomatic carriers, active chronic hepatitis, cirrhosis, and hepatocellular carcinoma. Hepat Mon. 2016; 16(6):34432.
2. Wu Y, Zhang J, Zhang H, et al. Hepatitis B virus X protein mediates yes-associated protein 1 upregulation in hepatocellular carcinoma. Oncol Lett. 2016;2(3):1971-1974.

3. Han C, Liao X, Qin W, et al. EGFR and SYNE2 are associated with $\mathrm{p} 21$ expression and SYNE2 variants predict post-operative clinical outcomes in HBV-related hepatocellular carcinoma. Sci Rep. 2016;6:31237.

4. Intaraprasong P, Siramolpiwat S, Vilaichone RK. Advances in management of hepatocellular carcinoma. Asian Pac J Cancer Prev. 2016;17(8): 3697-3703.

5. Yuan P, Chen P, Qian Y. Evaluation of antiviral therapy performed after curative therapy in patients with HBV-related hepatocellular carcinoma: an updated meta-analysis. Can J Gastroenterol Hepatol. 2016;2016:5234969.

6. Chen YJ, Lee YC, Huang CH, et al. Gallic acid-capped gold nanoparticles inhibit EGF-induced MMP-9 expression through suppression of p300 stabilization and NFKB/c-Jun activation in breast cancer MDA-MB-231 cells. Toxicol Appl Pharmacol. 2016;310:98-107.

7. Qiao Y, He H, Jonsson P, et al. AP-1 is a key regulator of proinflammatory cytokine $\mathrm{TNF} \alpha$-mediated triple-negative breast cancerprogression. J Biol Chem. 2016;291(35):18309.

8. Shin K, Kim KH, Yoon MS, et al. Expression of interactive genes associated with apoptosis and their prognostic value for ovarian serous adenocarcinoma. Adv Clin Exp Med. 2016;25(3):513-521. 
9. Davies CC, Chakraborty A, Diefenbacher ME, et al. Arginine methylation of the c-Jun coactivator RACO-1 is required for c-Jun/AP-1 activation. EMBO J. 2013;32(11):1556-1567.

10. Davies CC, Chakraborty A, Cipriani F, et al. Identification of a coactivator that links growth factor signalling to c-Jun/AP-1 activation. Nat Cell Biol. 2010;12(10):963-972.

11. Höner Zu Siederdissen C, Cornberg M. Management of HBV and HBV/ HDV-associated liver cirrhosis. Visc Med. 2016;32(2):86-94.

12. Zhang YQ, Peng LJ, Cao YR, et al. Risk factors for hepatocellular carcinoma in cirrhotic patients with chronic hepatitis B. Genet Test Mol Biomarkers. 2016;20(9):535-543.

13. Tawada A, Kanda T, Imazeki F, et al. Prevention of hepatitis B virus-associated liver diseases by antiviral therapy. Hepatol Int. 2016;10(4):574-593.
14. Qin Y, Zhong Y, Ma T, et al. Alteration of liver glycopatterns during cirrhosis and tumor progression induced by HBV. Glycoconj J. 2016;33(2):125-136.

15. Kao JH. Hepatitis B vaccination and prevention of hepatocellular carcinoma. Best Pract Res Clin Gastroenterol. 2015;29(6):907-917.

16. Liu Z, Wang J, Mao Y, et al. MicroRNA-101 suppresses migration and invasion via targeting vascular endothelial growth factor-C in hepatocellular carcinoma cells. Oncol Lett. 2016;11(1):433-438.

17. Li T, Zhu Y, Han L, et al. VEGFR-1 activation-induced MMP-9dependent invasion in hepatocellular carcinoma. Future Oncol. 2015; 11(23):3143-3157.

18. Takahashi Y, Ikeda N, Nakajima J, et al. Prognostic analysis of surgical resection for pulmonary metastasis from hepatocellular carcinoma. World J Surg. 2016;40(9):2178-2185. 


\section{Supplementary materials}

Table SI Correlations between RACO-I expression and clinicopathologic variables of 60 cases of HBV-related HCC in validation cohort

\begin{tabular}{|c|c|c|c|c|}
\hline \multirow[t]{2}{*}{ Clinicopathologic variables } & \multirow[t]{2}{*}{ Patients (n) } & \multicolumn{3}{|c|}{ RACO-I expression levels } \\
\hline & & Low & High & $P$-value \\
\hline \multicolumn{5}{|l|}{ Gender } \\
\hline Female & 19 & 9 & 10 & \multirow[t]{2}{*}{0.133} \\
\hline Male & 41 & 11 & 30 & \\
\hline \multicolumn{5}{|l|}{ Age (years) } \\
\hline$\leq 60$ & 50 & 15 & 35 & \multirow[t]{2}{*}{0.098} \\
\hline$>60$ & 10 & 5 & 5 & \\
\hline \multicolumn{5}{|l|}{ Liver cirrhosis } \\
\hline Presence & 31 & 6 & 25 & \multirow[t]{2}{*}{$0.04 I$} \\
\hline Absence & 29 & 14 & 15 & \\
\hline \multicolumn{5}{|l|}{ Tumor number } \\
\hline Solitary & 30 & 14 & 16 & \multirow[t]{2}{*}{0.046} \\
\hline Multiple & 30 & 6 & 24 & \\
\hline \multicolumn{5}{|l|}{ Tumor size } \\
\hline$\leq 5 \mathrm{~cm}$ & 28 & 8 & 20 & \multirow[t]{2}{*}{0.688} \\
\hline$>5 \mathrm{~cm}$ & 32 & 12 & 20 & \\
\hline \multicolumn{5}{|l|}{ Capsular formation } \\
\hline Presence & 29 & 14 & 15 & \multirow[t]{2}{*}{$0.04 I$} \\
\hline Absence & 31 & 6 & 25 & \\
\hline \multicolumn{5}{|l|}{ Vascular invasion } \\
\hline Presence & 26 & 3 & 23 & \multirow[t]{2}{*}{0.005} \\
\hline Absence & 34 & 17 & 17 & \\
\hline \multicolumn{5}{|l|}{ Edmondson-Steiner grade } \\
\hline Low grade (I-II) & 32 & 12 & 20 & \multirow[t]{2}{*}{0.721} \\
\hline High grade (III-IV) & 28 & 8 & 20 & \\
\hline \multicolumn{5}{|l|}{ UICC/AJCC stage } \\
\hline 1 & 25 & 12 & 13 & \multirow[t]{2}{*}{0.048} \\
\hline II-III & 35 & 8 & 27 & \\
\hline \multicolumn{5}{|l|}{ BCLC stage } \\
\hline $0-A$ & 27 & 15 & 12 & \multirow[t]{2}{*}{0.003} \\
\hline$B-C$ & 33 & 5 & 28 & \\
\hline
\end{tabular}

Note: $P<0.05$ was considered to be statistically significant, and the significant values are shown in bold.

Abbreviations: AJCC, American Joint Committee on Cancer; BCLC, Barcelona Clinic Liver Cancer; UICC, International Union for Cancer Control; RACO-I, RING domain AP-I coactivator-I; HBV, hepatitis B virus; HCC, hepatocellular carcinoma. 
Table S2 Univariable and multivariable analysis of factors in validation cohort associated with overall survival

\begin{tabular}{|c|c|c|c|c|c|}
\hline \multirow[t]{2}{*}{ Variables } & \multirow[t]{2}{*}{ Patients (n) } & \multicolumn{2}{|l|}{ Univariable analysis } & \multicolumn{2}{|c|}{ Multivariable analysis } \\
\hline & & HR (95\% Cl) & $P$-value & HR (95\% Cl) & $P$-value \\
\hline \multicolumn{6}{|l|}{ Gender } \\
\hline Female & 19 & I & & & \\
\hline Male & 41 & $1.743(0.646-4.703)$ & 0.274 & NA & NA \\
\hline \multicolumn{6}{|l|}{ Age (years) } \\
\hline$\leq 60$ & 50 & 1 & & & \\
\hline$>60$ & 10 & $1.264(0.842-1.898)$ & 0.418 & NA & NA \\
\hline \multicolumn{6}{|l|}{ Liver cirrhosis } \\
\hline Absent & 31 & I & & & \\
\hline Present & 29 & $1.208(0.367-3.976)$ & 0.528 & NA & NA \\
\hline \multicolumn{6}{|l|}{ Tumor number } \\
\hline Solitary & 30 & 1 & & & \\
\hline Multiple & 30 & $2.683(0.732-4.156)$ & 0.089 & NA & NA \\
\hline \multicolumn{6}{|l|}{ Tumor size } \\
\hline$\leq 5 \mathrm{~cm}$ & 28 & I & & & \\
\hline$>5 \mathrm{~cm}$ & 32 & $1.874(0.876-4.009)$ & 0.427 & NA & NA \\
\hline \multicolumn{6}{|l|}{ Capsular formation } \\
\hline Presence & 29 & I & & 1 & \\
\hline Absence & 31 & $2.287(1.732-3.020)$ & 0.048 & I.327 (0.93I-I.89I) & 0.076 \\
\hline \multicolumn{6}{|l|}{ Vascular invasion } \\
\hline Absent & 26 & 1 & & 1 & \\
\hline Present & 34 & $2.359(1.265-4.400)$ & 0.029 & $2.539(1.873-3.442)$ & 0.021 \\
\hline \multicolumn{6}{|c|}{ Edmondson-Steiner grade } \\
\hline Low grade (I-II) & 32 & I & & & \\
\hline High grade (III-IV) & 28 & $1.325(0.856-1.663)$ & 0.068 & NA & NA \\
\hline \multicolumn{6}{|l|}{ UICC/AJCC stage } \\
\hline I & 25 & 1 & & 1 & \\
\hline II-III & 35 & $2.464(1.905-3.187)$ & 0.021 & $2.643(1.735-4.026)$ & 0.031 \\
\hline \multicolumn{6}{|l|}{ BCLC stage } \\
\hline $0-A$ & 27 & I & & 1 & \\
\hline$B-C$ & 33 & $2.532(1.456-4.403)$ & 0.039 & $1.753(1.231-2.496)$ & 0.041 \\
\hline \multicolumn{6}{|l|}{ RACO-I expression } \\
\hline Low & 20 & 1 & & 1 & \\
\hline High & 40 & $1.936(1.533-4.238)$ & 0.031 & $2.052(1.435-2.934)$ & 0.029 \\
\hline
\end{tabular}

Note: $P<0.05$ was considered to be statistically significant; significant values are shown in bold.

Abbreviations: AJCC, American Joint Committee on Cancer; BCLC, Barcelona Clinic Liver Cancer; UICC, International Union for Cancer Control; RACO-I, RING domain AP-I coactivator-I; HR, hazard ratio; $\mathrm{Cl}$, confidence interval. 
Table S3 Univariable and multivariable analysis of factors in validation cohort associated with disease-free survival

\begin{tabular}{|c|c|c|c|c|c|}
\hline \multirow[t]{2}{*}{ Variables } & \multirow[t]{2}{*}{ Patients (n) } & \multicolumn{2}{|l|}{ Univariable analysis } & \multicolumn{2}{|c|}{ Multivariable analysis } \\
\hline & & HR (95\% Cl) & $P$-value & HR (95\% Cl) & $P$-value \\
\hline \multicolumn{6}{|l|}{ Gender } \\
\hline Female & 19 & I & & & \\
\hline Male & 41 & $1.328(0.395-3.542)$ & 0.329 & NA & NA \\
\hline \multicolumn{6}{|l|}{ Age (years) } \\
\hline$\leq 60$ & 50 & 1 & & & \\
\hline$>60$ & 10 & I.68I (0.787-2.252) & 0.535 & NA & NA \\
\hline \multicolumn{6}{|l|}{ Liver cirrhosis } \\
\hline Absent & 31 & 1 & & & \\
\hline Present & 29 & $1.268(0.688-3.127)$ & 0.631 & NA & NA \\
\hline \multicolumn{6}{|l|}{ Tumor number } \\
\hline Solitary & 30 & 1 & & & \\
\hline Multiple & 30 & $2.28 \mathrm{I}(0.868-3.689)$ & 0.535 & NA & NA \\
\hline \multicolumn{6}{|l|}{ Tumor size } \\
\hline$\leq 5 \mathrm{~cm}$ & 28 & 1 & & & \\
\hline$>5 \mathrm{~cm}$ & 32 & $1.431(0.627-2.758)$ & 0.595 & NA & NA \\
\hline \multicolumn{6}{|l|}{ Capsular formation } \\
\hline Presence & 29 & I & & 1 & \\
\hline Absence & 31 & $1.658(1.217-3.268)$ & 0.045 & $1.212(0.919-3.278)$ & 0.078 \\
\hline \multicolumn{6}{|l|}{ Vascular invasion } \\
\hline Absent & 26 & I & & 1 & \\
\hline Present & 34 & $2.215(1.364-3.182)$ & 0.008 & $2.378(I .468-4.27 I)$ & 0.013 \\
\hline \multicolumn{6}{|c|}{ Edmondson-Steiner grade } \\
\hline Low grade (I-II) & 32 & 1 & & & \\
\hline High grade (III-IV) & 28 & I.I $88(0.890-2.685)$ & 0.275 & NA & NA \\
\hline \multicolumn{6}{|l|}{ UICC/AJCC stage } \\
\hline 1 & 25 & 1 & & 1 & \\
\hline II-III & 35 & $2.209(1.338-3.817)$ & 0.017 & $2.129(1.210-4.644)$ & 0.039 \\
\hline \multicolumn{6}{|l|}{ BCLC stage } \\
\hline $0-A$ & 27 & 1 & & & \\
\hline$B-C$ & 33 & $1.367(1.121-3.017)$ & 0.022 & $1.415(1.123-3.684)$ & 0.037 \\
\hline \multicolumn{6}{|l|}{ RACO-I expression } \\
\hline Low & 20 & I & & 1 & \\
\hline High & 40 & $2.175(1.198-4.128)$ & 0.016 & $2.156(1.338-3.985)$ & 0.028 \\
\hline
\end{tabular}

Note: $P<0.05$ was considered to be statistically significant; significant values are shown in bold.

Abbreviations: AJCC, American Joint Committee on Cancer; BCLC, Barcelona Clinic Liver Cancer; UICC, International Union for Cancer Control; RACO-I, RING domain AP-I coactivator-I; HR, hazard ratio; $\mathrm{Cl}$, confidence interval.

\section{Publish your work in this journal}

Therapeutics and Clinical Risk Management is an international, peerreviewed journal of clinical therapeutics and risk management, focusing on concise rapid reporting of clinical studies in all therapeutic areas, outcomes, safety, and programs for the effective, safe, and sustained use of medicines. This journal is indexed on PubMed Central, CAS,
EMBase, Scopus and the Elsevier Bibliographic databases. The manuscript management system is completely online and includes a very quick and fair peer-review system, which is all easy to use. Visit http://www.dovepress.com/testimonials.php to read real quotes from published authors. 